\title{
Challenges in Pain Management in Palliative Care
}

\author{
Pallavi Ahluwalia ${ }^{1}$ \\ ${ }^{1}$ Professor, Department of Anaesthesia, Teerthanker Mahaveer Medical College, TMU, Moradabad.
}

The main aim of Palliative care is to provide the best possible quality of life to the person approaching the end of life and also support their families and caregivers. Palliative care is a holistic approach to provide care and support. Palliative care is like an umbrella which takes into account emotional, psychological and spiritual needs as well as physical needs. The core concept of palliative care is pain control. Freedom From Pain helps patient to cope up and enables them to make arrangements for the future of others who depend on them, as well as to live as fully as possible for as long as possible. Very beautifully expressed that "Where pain ends- the life begins".

WHO has defined the palliative care as an approach that: Affirms life and regards death as a normal process, does not hasten or postpone death, provides relief from pain and other symptoms, offers a support system to help patients live as actively as possible right up to their death, integrates psychological and spiritual care, provides a wider support to help the family cope during the patient's illness and their own bereavement after death.

Opioids are indispensable for the management of moderate and severe pain in patients with advanced medical illness or cancer. Opioid analgesics are now considered as the standard of care in most of the world. ${ }^{[1,2]}$

The most critical aspect of effective pain management is easy availability and access to opioid medication .Other aspects such as adequate treatment of opioid dependence and quality of palliative care are equally important. Unfortunately, statistics estimate that more than $80 \%$ of the world population is inadequately treated for pain mainly because of difficulties in accessing opioids. ${ }^{[3-7]}$ The data has revealed that barriers to opioid access are pandemic, multifaceted, and primarily associated with overly restrictive laws, regulations, and licensing requirements. ${ }^{[8]}$ The availability issues such as limitation at the level of distribution among populations and areas in need and accessibility that is the level of obtainment with the least possible regulatory, social, or psychological obstacles to opioid medication worldwide; need an effective solution. The key solution requires newer policy-related strategies aiming to implement new regulations or to maintain existing provisions that are defined in laws and legally binding documents. ${ }^{[9-11]}$
We can thus broadly classify barriers that interfere with adequate pain management into three subheads. Problems related to health care professionals, problems related to patients, and to the health care system.

\section{Problems Related to Health Care Professionals}

Inadequate assessment of pain and lack of knowledge on the part of clinicians are the major barriers to cancer pain treatment. $^{[12]}$

Physicians and nurses play a major role in decision making during cancer pain management. Physicians education can improve their assessment of patients' pain and that may inturn result in adequate analgesic prescription and better pain management. ${ }^{[13]}$.

Other aspects such as anxiety about regulation of controlled substances, concerns about the side effects of analgesics, and fear of patients becoming addicted or tolerant to analgesics need to be tackled. There is an immense need for improved training in cancer pain management at all levels of professional education. Just a small step like inclusion of pain score/assessment along with vital signs, would definitely improve pain management by physicians and nurses. Pain assessment should be given the attention it deserves.

\section{Problems Related to Patients}

Patients may not complain of pain because they want to be a "good" patient, or they are reluctant to distract the physician from treating the primary disease. They may think of pain as an inevitable part of having cancer, or they may not want to recognize that their disease is progressing. ${ }^{[14]}$.

Many patients also fear that early pain control will preclude pain control later in the disease because of concerns (which their physicians often share) that they will become tolerant to pain medications.

Patients are often reluctant to take pain medication, and some fear addiction or being perceived as an addict. Worries about unmanageable side effects can result in poor adherence to the prescribed analgesic regimen.

\section{Problems Related to the Health Care System}

A strict regulatory environment that closely monitors physicians' prescribing is a major barrier that leads to under treatment of cancer pain. Restrictive regulation of controlled substances and problems of availability of treatment are other obstacles in patient care. A survey of Wisconsin 
physicians found that, due to concerns about regulatory scrutiny, most respondents reduce the drug dose or the quantity of pills prescribed, limit the number of refills, or choose a drug in a lower schedule. Very low priority is given to cancer pain treatment in the health system and in the training curriculum of health professionals.

Majority of medical and nursing textbooks devote only a few pages to current pain control guidelines. Health policy issues that are related to pain for example the cost, the access to care, regulatory perspectives, ethical and legal issues, have been neglected.

The World Health Organization has an immense impact in changing policies on cancer pain relief but still today, in many parts of the world, even simple analgesics are not available for cancer pain, let alone morphine.

The most appropriate treatment may not be reimbursed or may be too costly for patients and their families in many countries. The available data suggests that lack of coverage and uneven reimbursement policies for health care, including prescription drugs, medical equipment, and professional services is responsible for limited access to acute and cancer pain management for millions of people, in particular the poor, elderly, and minorities.

It is very essential to identify the severity of barriers to effective cancer pain management in different countries and determine the priorities for eliminating them in order to improve cancer pain management for all those in need.

If international priorities on improving pain management at the end

of life are to be achieved, educational opportunities for generalists need to be

enhanced, and effective inter-professional working models need to be developed

so that pain management for patients at the end of life is optimized.

The three foundation measures to scaling up the provision of such care as recognized by WHO are :

\section{Development of a national policy.}

Palliative care is not recognized in many government plans. For example, Uganda is the only country in sub-Saharan Africa that has adopted WHO's foundation measures for establishing a palliative care service. While a handful of other countries in the region have some provision for palliative care, this is provided outside the government health service. Provision of palliative care as part of the essential health service system by the government will be a move towards ensuring some budget allocation for provision of care for those with chronic illnesses.

2. Training for health workers and public education. Basic understanding of what palliative care is, and training to carry it out is very necessary for policy makers, health professionals and families.

3. Pain control. Pain management is an important aspect in cancer patients. In many countries, effective pain management will require training and awareness raising among health professionals, and advocacy to change laws to make effective pain relief available.
Home care schemes are often seriously under-resourced, and while there is no doubt that they help to ease suffering (and if nothing else is available can provide accompaniment and spiritual comfort), it is important that home care schemes are helped and upgraded. It is seen that home care models have a great potential, through partnerships and working with governments, to provide a platform from which proper provision of palliative care can be started. But it is also important that home care, in the sense of providing some minimal level of support, is not confused with provision of palliative care.

Hospitals should have a multidisciplinary policy and procedure for assessment of pain, prescribing or ordering analgesics, and pain management algorithms. There should be an auditing system to measure effectiveness of pain management by nurses. This can be done through chart audit and their knowledge test about pain management.

Despite the growing evidence on pain management and the availability of evidence-based clinical guidelines, pain is still inadequately treated. This can be attributed to lack of knowledge among health professionals, misconceptions among patients, \& lack of guidelines. Education of patients and health care professionals and adherence to clinical guidelines are paramount for effective pain management. Pain Management is a fundamental Human right that can be improved with proper education, adopting universal pain management standards, making legislative reforms, liberalization of national policies on opioid availability, provision of affordable opioids, adopting Pain control programs in all nations and continued WHO activism.

\section{References}

1. Rosenblum A, Marsch LA, Herman J, Portenoy RK. Opioids and the treatment of chronic pain: controversies, current status and future directions. Exp Clin Psychopharmacol 2008;16:405e416.

2. Bosnjak S, Mauer MA, Ryan KM, et al. Improving the availability and accessibility of opioids for the treatment of pain: the International Pain Policy Fellowship. Support Care Cancer 2011;19:1239e1247.

3. Joranson DE, Ryan KM, Maurer M. Opioid policy, availability, and access in developing and non-industialized countries. In: Fishman SM, Ballantyne JC, Rathmell JP, eds. Bonica's Management of Pain, 4th ed Baltimore, MD: Lippincott Williams \& Wilkins, 2010:194e208.

4. Fallon M, Cherny NI, Hanks G. Opioid analgesic therapy. In: Hanks G, Cherny NI, Christakis NA, Fallon M, Kaasa S, Portenoy RK, eds. Oxford Textbook of Palliative Medicine, 4th ed New York: Oxford University Press, 2010: 661e698.

5. Milani B, Scholten W. The world medicines situation 2011: Access to controlled medicines, 3rd ed. Geneva: World Health Organization, 2011.

6. Silbermann M. Current trends in opioid consumption globally and in Middle Eastern countries. J Pediatr Hematol Oncol 2011;33:S1eS5.

7. Vigil IT, Aday LA, De Lima L. What predicts the quality of advanced cancer care in Latin America? A look at five countries: Argentina, Brazil, Cuba, Mexico, and Peru. J Pain Symptom Manage 2007;34:315e327.

8. LeBaron V, Beck S, Maurer M, et al. An ethnographic study of barriers to cancer pain management and opioid availability in India. Oncologist 2014;19:515e522.

9. World Health Organization. Ensuring balance in national policies on controlled substances: Guidance for availability and accessibility of controlled medicines. Geneva: WHO, 2011. Available at: http://whqlibdoc.who.int/publications/2011/9789241564175_eng.pd f. Accessed December 17, 2014. 


\section{Ahlunalia, Pain Management in Palliative Care}

10. Gilson AM, Maurer MA, LeBaron VT, Ryan KM, Cleary JF. Multivariate analysis of countries' government and health-care system influences on opioid availability for cancer pain relief and palliative care: more than a function of human development. Palliat Med 2013;27:105e114.

11. Latypov A, Bidordinova A, Khachatrian A. Opioid substitution therapy in Eurasia: How to increase the access and improve the quality. IDPC briefing series on drug dependence treatment no 1 . United Kingdom: IDPC, 2012. Available at: http://idpc.net/publications/201 /01/ idpc-briefing-ost-in-eurasia. Accessed July 18, 2015.
12. Bruera E, Willey JS, Ewert-Flannagan PA, Cline MK, Kaur G, Shen L, Zhang T, Palmer JL. Pain intensity assessment by bedside nurses and palliative care consultants: a retrospective study. Support Care Cancer 2005;13:228-31.

13. Cleeland CS, Cleeland LM, Dar R, Rinehardt LC. Factors influencing physician management of cancer pain. Cancer 1986;58:796-800.

14. Hodes R. Cancer patients' needs and concerns when using narcotic analgesics. In: Hill CS, Fields WS, editors. Drug treatment of cancer pain in a drug-oriented society. Advances in Pain Research and Therapy, Vol. 11. New York: Raven Press; 1989:91-9.

Copyright: (C) the author(s), publisher. Academia Anesthesiologica International is an Official Publication of "Society for Health Care \& Research Development". It is an open-access article distributed under the terms of the Creative Commons Attribution Non-Commercial License, which permits unrestricted non-commercial use, distribution, and reproduction in any medium, provided the original work is properly cited.

How to cite this article: Ahluwalia P. Challenges in Pain Management in Palliative Care. Acad. Anesthesiol. Int. 2018;3(1):1-3.

DOI: dx.doi.org/10.21276/aan.2018.3.1.1

Source of Support: Nil, Conflict of Interest: None declared. 